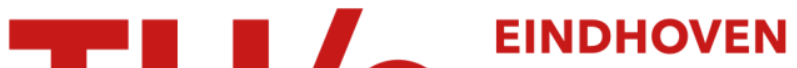 UNIVERSITY OF TECHNOLOGY
}

\section{An opposed jets device for studying the breakup of dispersed liquid drops}

\section{Citation for published version (APA):}

Janssen, J. M. H., Peters, G. W. M., \& Meijer, H. E. H. (1993). An opposed jets device for studying the breakup of dispersed liquid drops. Chemical Engineering Science, 48(2), 255-265. https://doi.org/10.1016/00092509\%2893\%2980013-G, https://doi.org/10.1016/0009-2509(93)80013-G

\section{DOI:}

10.1016/0009-2509\%2893\%2980013-G

10.1016/0009-2509(93)80013-G

\section{Document status and date:}

Published: 01/01/1993

\section{Document Version:}

Publisher's PDF, also known as Version of Record (includes final page, issue and volume numbers)

\section{Please check the document version of this publication:}

- A submitted manuscript is the version of the article upon submission and before peer-review. There can be important differences between the submitted version and the official published version of record. People interested in the research are advised to contact the author for the final version of the publication, or visit the $\mathrm{DOI}$ to the publisher's website.

- The final author version and the galley proof are versions of the publication after peer review.

- The final published version features the final layout of the paper including the volume, issue and page numbers.

Link to publication

\section{General rights}

Copyright and moral rights for the publications made accessible in the public portal are retained by the authors and/or other copyright owners and it is a condition of accessing publications that users recognise and abide by the legal requirements associated with these rights.

- Users may download and print one copy of any publication from the public portal for the purpose of private study or research.

- You may not further distribute the material or use it for any profit-making activity or commercial gain

- You may freely distribute the URL identifying the publication in the public portal.

If the publication is distributed under the terms of Article 25fa of the Dutch Copyright Act, indicated by the "Taverne" license above, please follow below link for the End User Agreement:

www.tue.nl/taverne

Take down policy

If you believe that this document breaches copyright please contact us at:

openaccess@tue.nl

providing details and we will investigate your claim. 


\title{
AN OPPOSED JETS DEVICE FOR STUDYING THE BREAKUP OF DISPERSED LIQUID DROPS
}

\author{
J.M.H. JANSSEN, G.W.M. PETERS and H.E.H. MEIJER \\ Eindhoven University of Technology, \\ Department of Fundamental Mechanical Engineering, \\ P.O. Box 513, $5600 \mathrm{MB}$, The Netherlands.
}

\begin{abstract}
Many studies on the dispersion of one liquid in another concentrate on the deformation and breakup of a single drop in a well defined flow. This paper describes the design of a device, which has not yet been used in this field. The concept makes use of the stagnation flow of two opposed jets in a closed circuit. A numerical study results in channel geometries for plane hyperbolic flow, which is purely extensional, and for a flow type which combines extension and vorticity. A device with dimensions of several centimeters suffices to study deformation of a $1 \mathrm{~mm}$ drop. Experiments show that the model for plane hyperbolic flow is obeyed in a large region around the stagnation point. A control system is developed to position the deforming drop steadily at the, principally unstable, stagnation point. A control cycle consists of determination of the drop position and calculation and realization of the required flow adjustment. In the present experimental setup the deformation of a drop in 2-dimensional elongational flow can be studied via video recording. The setup chosen not only allows for model liquids but can be adjusted to allow for polymer melts as well.
\end{abstract}

\section{KEYWORDS}

Dispersive mixing; drop breakup; elongational flow; opposed jets.

\section{INTRODUCTION}

\section{Dispersive Mixing}

The dispersion of one liquid in another is an essential subject in many industrial processes involving multiphase flow. For example, in the melt blending of incompatible polymers, the morphology of the biend is of major influence on its mechanical (and other) properties. Therefore, it is important to model the development of the morphologies during the mixing process; starting with large $(\mathrm{mm})$ domains of a distinguished liquid phase (dispersed phase) and ending with a distribution of small $(\mu \mathrm{m})$ domains of the dispersed phase in a continuous matrix phase.

A classical way to model the dispersive mixing process is to study the deformation and breakup of a single drop of the dispersed phase in a well defined flow field of the continuous phase. The dimensionless results of such analyses may be converted to real processes involving many drops and complicated flow fields. Deformation of a drop, suspended in an immiscible liquid, is due to the flow induced stresses acting on it and is 
counteracted by the interfacial tension between the two phases, which tends to keep the drop spherical. In order to study the influences of various parameters such as stress, (ratio of) viscosities, viscoelasticity, interfacial tension, and time, it is tractable to use model liquids and model flows.

Model liquids can be handled at room temperature, in contrast to molten polymers. Moreover, they offer the opportunity to control the rheological properties, such as the viscous, shear thinning, or viscoelastic behavior. Some of the flow types used in experimental or numerical investigations are simple shear flow, generated in a parallel band (Taylor, 1934) or a Couette device (Grace, 1971), plane hyperbolic or 2-D elongational flow, generated in a four roll mill (Grace, 1971; Bentley and Leal, 1986), and 3-D axisymmetric elongational flow, often used in numerical studies (Rallison, 1984). The present study concerns the design of a so-called 'opposed jets device', for the experimental study of drop deformation in 2-D elongational flow. Generally, in real processes the flow is a complex combination of all these types of flow.

\section{Linear 2-D Flows}

Most of the flow types used experimentally are linear 2-D flows. In general, a linear 2-D flow can be described by the velocity vector

$$
\overrightarrow{\mathrm{u}}=(\vec{\nabla} \overrightarrow{\mathrm{u}})^{\mathrm{c}} \cdot \overrightarrow{\mathrm{x}}=\mathbf{L} \cdot \overrightarrow{\mathrm{x}}
$$

where $\vec{\nabla}$ is the gradient vector operator, $\vec{x}$ the position vector, and $\mathrm{L}$ the velocity gradient tensor (Giesekus, 1962; Fuller and Leal, 1981)

$$
\mathrm{L}=\frac{\mathrm{G}}{2}\left[\begin{array}{ccc}
1+\alpha & 1-\alpha & 0 \\
-1+\alpha & -1-\alpha & 0 \\
0 & 0 & 0
\end{array}\right], \quad \text { with }-1 \leq \widehat{\alpha \leq \mathrm{I}}
$$

In a Cartesian coordinate system $\vec{x}(x, y, z)$ the components of $\vec{u}(u, v, w)$ are

$$
\mathrm{u}=\frac{\mathrm{G}}{2}[(1+\alpha) \mathrm{x}+(1-\alpha) \mathrm{y}], \mathrm{v}=\frac{\mathrm{G}}{2}[(-1+\alpha) \mathrm{x}+(-1-\alpha) \mathrm{y}], \mathrm{w}=0
$$

$\mathrm{G}\left(\mathrm{s}^{-1}\right)$ is the velocity gradient. The value of $\alpha$ indicates the type of flow, ranging from purely rotational $(\alpha=-1)$ via simple shear $(\alpha=0)$ to plane hyperbolic flow $(\alpha=1)$; see, e.g., Bentley (1985). Using the common definitions of the rate of elongation, the rate of shear, and the vorticity, Janssen (1991) elaborated some properties of linear 2-D flows in general. This paper is mainly restricted to plane hyperbolic flow $(\alpha=1)$, which is the strongest in terms of deformation. Substituting $\alpha=1$, the velocity field equals

$$
\mathrm{u}=\mathrm{Gx}, \quad \mathrm{v}=-\mathrm{Gy}, \quad \mathrm{w}=0 .
$$

Although the velocity $\vec{u}$ equals zero at $\vec{x}=\overrightarrow{0}$, a deforming drop tends to leave this stagnation point along the positive or negative $\mathrm{x}$-axis. The stagnation point is principally unstable since the velocity gradient tensor $L$ has an eigenvector with positive eigenvalue along the $\mathrm{x}$-axis. The rates of elongation and of shear are (for $\alpha=1$ ) given by

$$
\begin{aligned}
& \dot{\epsilon}=\mathrm{G} \cos (2 \phi), \\
& \text { and } \quad \dot{\gamma}=\mathrm{G} \sin (2 \phi),
\end{aligned}
$$

where $\phi$ is the angle with respect to the positive $\mathrm{x}$-axis. So, in plane hyperbolic flow, maximum extension appears at the $x$-axis and maximum compression at the $y$-axis. The rate of shear has its extrema at the diagonals, where the rate of elongation equals zero. The entire flow field is free of vorticity, i.e. irrotational. 
The conventional four roll mill is flexible in generating all types of linear 2-D flows (Bentley and Leal, 1986). However, a disadvantage is its complexity: the roller speeds not only determine $\mathrm{G}$ and $\alpha$ but are also used to keep the deforming drop positioned at the centre of the device. Moreover, a four roll mill does not allow for highly viscoelastic fluids because the shear stresses generated by the rotating rollers may be too weak to overcome the large extensional stresses that appear; so, the fluid may not enter the compartment in between the rollers (Metzner and Metzner, 1970). Finally, it will be difficult to use molten polymers (at 200 to $300^{\circ} \mathrm{C}$ ) in a four roll mill with its large volume of fluid and four mobile parts. The high temperatures may cause degradation of the polymer while high viscosities $\left(10^{2}\right.$ to $\left.10^{4} \mathrm{Ns} / \mathrm{m}^{2}\right)$ ask for very powerful drives.

\section{The Concept of the Opposed Jets Device}

The aim of the present study is to design a device which can generate linear 2-D flows (in particular plane hyperbolic flow), but is smaller and easier to construct and to operate than the four roll mill and which has the potential to be suitable for experiments with (highly) viscoelastic fluids. It is not new to apply the stagnation flow of opposed jets in order to generate an elongational flow (Müller et al., 1988). However, this concept (as shown in Fig. 1) has never been used in drop deformation studies.

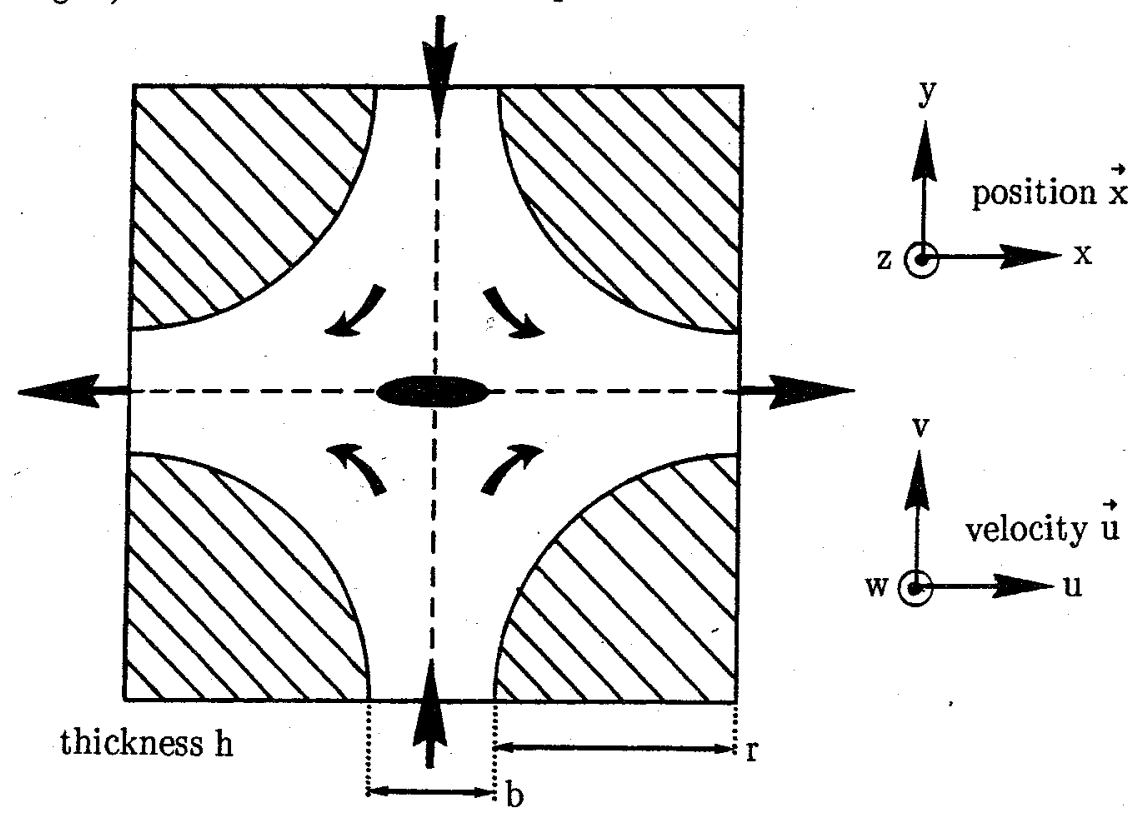

Figure 1. Principle of the opposed jets device for drop deformation in plane hyperbolic flow.

The liquid is pumped from two opposite directions into a cell with a specific shape; the two flows impinge and leave the cell via two opposite exits. The cell consists of four solid blocks (thickness h), between two parallel plates of Perspex or glass (for optical access). The entrances and exits have all rectangular cross-sections $(b \times h)$ and are connected to a pump and a tank respectively. The $2-D$ character of the flow may be achieved around the midplane $(z=0)$ for sufficiently large $h / b$. Differently shaped cells cause different types of flow.

In comparison with the four roll mill, the opposed jets device is thought to generate a similar flow field in the central region. The three functions $G, \alpha$, and the position control of the drop, which are all related to the roller speeds in the four roll mill, are completely independent in the opposed jets device: the velocity gradient $\mathrm{G}$ is determined by the flow rate, the flow type parameter $\alpha$ is related to the shape of the cell, and the position control is governed by the ratio of the exit flow rates, as discussed later. Separation of these functions makes the device less complex than a computer controlled four roll mill. 
Furthermore, the opposed jets device is expected to allow for highly viscoelastic fluids, in contrast to the four roll mill. The fluid is forced directly into the cell instead of driven indirectly via the rollers. The closed and small volume in the fixed opposed jets cell is quite suitable for polymer melts as well. The main disadvantage of the opposed jets device, however, is the fact that a different shaped cell has to be installed in order to change the type of flow. For this purpose, the four roll mill is more adequate.

\section{DESIGN OF THE GEOMETRY}

\section{Strategy}

The first step is to select geometries which can generate different types of linear 2-D flows, at least in the central region and for Newtonian liquids. From a number of numerical flow simulations a set of geometries is selected of which the calculated streamlines compare qualitatively well with those derived from the flow model. After this qualitative design of the geometries, the dimensions have to be chosen quantitatively to get a device which fulfills the demands from drop deformation experiments (Rumscheidt and Mason, 1962; Grace, 1971; de Bruin, 1989; van der Reijden-Stolk, 1989; Elemans,1989): a central region of constant (within 10\%) velocity gradient G. Given the typical diameter of a drop: $1 \mathrm{~mm}$, which should be homogeneously elongated by at least a factor 10 without reaching a deviating flow type, this region of constant G should be 1 to $1.5 \mathrm{~cm}$ square. Furthermore, the value of $G$ should be of the order $1 \mathrm{~s}^{-1}$, to be able to sufficiently deform a drop. Moreover, the total volume should be as small as possible in order to make the device suitable for polymer melts.

The flow was simulated with Sepran (Segal, 1989), a finite element package. The program iteratively solves the 2-D Navier-Stokes and continuity equations for a stationary incompressible Newtonian flow, using the penalty function method. First, the solution is obtained in terms of the velocity field. Based on this solution the pressure, streamfunction, vorticity, and rates of elongation and of shear are derived. The mesh consists of quadratic triangles. The values of $\mathrm{G}$ and $\alpha$ can be determined from comparison of the extrema of the rates of elongation and of shear and the vorticity to their profiles as derived from the model (Janssen 1991).

\section{Numerical Results}

The geometries consist of circular parts and have extended entrances and exits, representing the tube connections and allowing an entering plug flow (boundary condition) to develop into a steady velocity profile. A tube length of half its width $b$ is enough for the flow to develop since the Reynolds number is small (typically $O(1)$ ). For the $\alpha=1$ geometry, the ratio $\mathrm{r} / \mathrm{b}$ (Fig. 1 ) is set 2 to make the circular parts reasonably fit to hyperboles (Bentley, 1985). In the first series of calculations the density is $10^{3}$ $\mathrm{kg} / \mathrm{m}^{3}$, the dynamic viscosity $5 \mathrm{Ns} / \mathrm{m}^{2}$, the velocity at both entrances is a plug flow of 1 $\mathrm{m} / \mathrm{s}$, and the channel width $\mathrm{b}=4 \mathrm{~cm}$. To get a quick first impression of the flow field, the convective (non-linear) term of the Navier-Stokes equation is neglected, resulting in a set of linear equations solvable without iterations (Stokes flow). For low Reynolds flows, this simplification should be of minor influence. Still, the calculations for the quantitative dimensioning involve the complete Navier-Stokes equation.

Plane hyperbolic flow $(\alpha=1)$ is easily generated in a square setup of 4 quarters of circles. Figure 2.a presents the streamlines for this case. In the central region the streamlines appear to be hyperboles with perpendicular asymptotes. The rates of elongation and of shear have their extrema and symmetry as expected from theory while the centre is free of vorticity. In this case, the approximate value of $\mathrm{G}$ amounts to $17 \mathrm{~s}^{-1}$.

Another geometry was shaped for the particular flow type $\alpha=0.6$, thus containing a certain amount of vorticity. This was realized by 'forcing' the streamline asymptotes to intersect at $75.5^{\circ}$, as required by the flow model. Starting with a rhomb setup of circular parts, the small circles are reduced and shifted one channel width (b) inward, the large 
circles enlarged and shifted outward (Fig. 2.b). This results in a pattern of streamlines that obeys the desired asymptotes in a large area around the stagnation point. From the complete results of the rates of elongation and of shear and the vorticity, the values of $G$ and $\alpha$ are evaluated: $\mathrm{G}=20 \mathrm{~s}^{-1}$ and $\alpha=0.55$. It is evident that the streamlines give a reliable impression of the flow type; a geometry may be classified unsuitable if the streamlines do not coincide with the desired ones. Now it has been shown to be possible to design a geometry for $\alpha=0.6$, it seems possible to design geometries for all linear 2-D flows in between plane hyperbolic and simple shear flow $(0<\alpha<1)$. Although in this paper only plane hyperbolic flow $(\alpha=1)$ has been fully elaborated, it is essential to show the possibility of intermediate flow types using the principle of opposed jets. Such types of flow may be of particular interest in dispersive mixing since practical flows generally are combinations of elongation and shear.
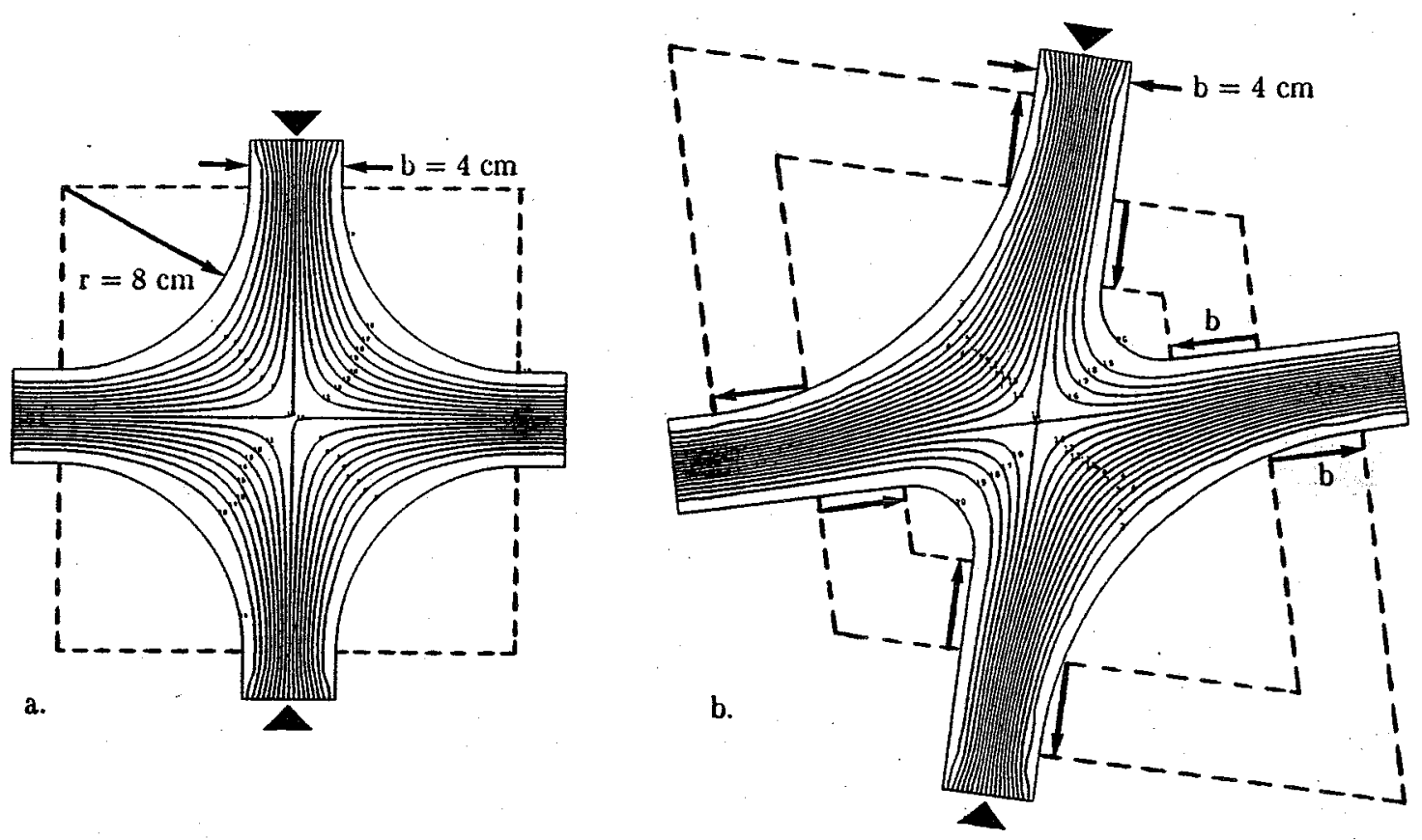

Figure 2. Streamlines in geometries suitable for a. $\alpha=1$ and b. $\alpha=0.6$.

The designed shapes have to be dimensioned in accordance with the requirements stated before. An evaluation of the complete results from the calculations in Fig. 2 shows that for a plug flow of $1 \mathrm{~m} / \mathrm{s}$ through entrances of width $\mathrm{b}=4 \mathrm{~cm}$ the region of constant $( \pm 10 \%)$ velocity gradient is about $6 \mathrm{~cm}$ along the $\mathrm{x}$ - and $\mathrm{y}$-axis while $\mathrm{G} \approx 20 \mathrm{~s}^{-1}$. According to the requirements the length scale may now be diminished by a factor 4 and the velocity by a factor 80 . The case of a plug flow of $1 / 80 \mathrm{~m} / \mathrm{s}$ through channels with $\mathrm{b}$ $=1 \mathrm{~cm}$ is expected to give a region of about $1.5 \mathrm{~cm}$ where $\mathrm{G}=1 \mathrm{~s}^{-1}$. The newly scaled geometries for $\alpha=1$ and $\alpha=0.6$ are subjected to an analysis with the complete Navier-Stokes equation. As expected, the non-linear term is of no influence on the Stokes solution for this low Reynolds flow (after scaling: $R e=O(0.1)$ ).

For $\alpha=1$ the two planes of symmetry are used in order to limit the computing time for the iterative solution process; only one quarter of the geometry is taken into account. This also allows for a mesh refinement towards the centre. Figure 3 presents the complete results. Within the drawn box the flow corresponds to the linear 2-D flow model. This means that the region of constant $( \pm 10 \%)$ velocity gradient at the centre is a square of $b x$ $\mathrm{b}(\mathrm{b}=1 \mathrm{~cm})$. From the results it is seen that this central region is completely irrotational $(\alpha=1.0)$ and $\mathrm{G}=1.0 \mathrm{~s}^{-1}$. Also the scaled $\alpha=0.6$ geometry gives satisfactory results: using a plug flow entrance velocity of $0.0125 \mathrm{~m} / \mathrm{s}$ through channels of width $b=1 \mathrm{~cm}$, the value of $\alpha$ is determined to be 0.54 while $G=1.0 \mathrm{~s}^{-1}$ in the central region of $b \times b$. 

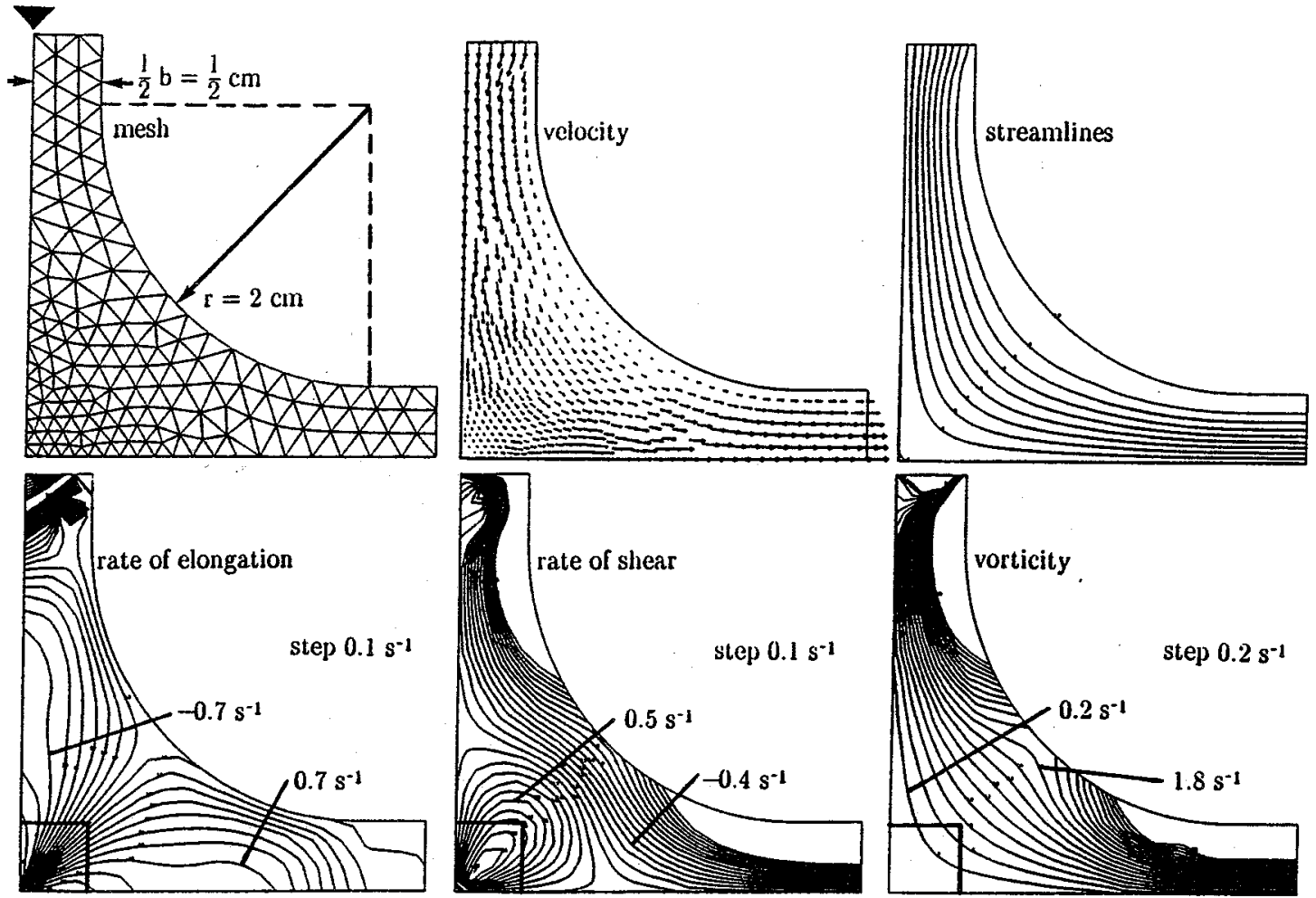

Figure 3. Complete results for the scaled $\alpha=1$ geometry; plug flow entrance velocity $0.0125 \mathrm{~m} / \mathrm{s}$; channel width $\mathrm{b}=1 \mathrm{~cm}$; drawn box $0.5 \mathrm{~cm} \times 0.5 \mathrm{~cm}$.

As long as the Reynolds number stays of the order $O(0.1)$, the viscosity is not expected to significantly affect the flow pattern. This is verified by solving the problem for $\alpha=1$ with viscosity 1 instead of $5 \mathrm{Ns} / \mathrm{m}^{2}$. The velocity solution and all derived parameters appear to stay identical. Only the pressure diminishes by a factor 5 . Based on the above calculations, it is possible to relate the velocity gradient $G$ in the central region of the opposed jets device to the total flow rate supplied by the pump. Analysis of the fully developed flow in the rectangular entrance channels (Berker, 1963; White, 1974) gives a correlation between the total flow rate $\mathrm{Q}$ and the quasi plug flow velocity in the midplane $(z=0)$ of the entrances; this 2-D entrance velocity determines the velocity gradient $G$ in the midplane of the cell, as determined by the simulations. Dependent on the cell thickness $\mathrm{h}$, the proportionalities read

$$
\begin{aligned}
& \mathrm{G}\left(\mathrm{s}^{-1}\right)=0.266 \cdot 10^{6} \mathrm{Q}\left(\mathrm{m}^{3} / \mathrm{s}\right) \quad \text { for } \mathrm{h}=2 \mathrm{~cm} \\
& \text { and } \mathrm{G}\left(\mathrm{s}^{-1}\right)=0.118 \cdot 10^{6} \mathrm{Q}\left(\mathrm{m}^{3} / \mathrm{s}\right) \\
& \text { for } \mathrm{h}=4 \mathrm{~cm} \text {. }
\end{aligned}
$$

In fact, the 2-D numerical simulations cannot be fuliy valid in a real 3-D cell. Still, in the midplane (plane of symmetry) between the flat front and back plates the 2-D simulation seems a quite good approximation, certainly on the scale of a deforming drop $(1 \mathrm{~mm})$ in comparison with a cell thickness of 2 or $4 \mathrm{~cm}$. Few 3-D simulations pointed out that at least up to $\mathrm{G}=10 \mathrm{~s}^{-1}$ the velocity component $\mathrm{w}$ is negligible if compared to $\mathrm{u}$
and $\mathrm{v}$.

In addition to the above computations, also the flow in the four roll mill has been analysed for $\alpha=1$ (plane hyperbolic flow). Dimensions, fluid properties, and velocities are comparable to those in Fig. 3 . Surprisingly, the velocity gradient in the central region of the four roll mill is much less uniform than in the opposed jets device. 


\section{Equipment}

Two cells were built to generate plane hyperbolic flow, both constructed of 4 solid blocks between two parallel Perspex plates. The inner volume is enclosed by 4 quarters of circles and has dimensions: radius $\mathrm{r}=2 \mathrm{~cm}$, channel width $\mathrm{b}=1 \mathrm{~cm}$, and thickness $\mathrm{h}=2 \mathrm{~cm}$ (prototype cell with aluminum blocks) or $\mathrm{h}=4 \mathrm{~cm}$ (final design with Perspex blocks). The 4 entrance and exit channels have a rectangular cross-section $(1 \mathrm{~cm} \times 4 \mathrm{~cm})$ over a length of $8 \mathrm{~cm}$ and then gradually change into circular tubes, ensuring full development of the flow. The cell is positioned with its exits ( $x$-axis) vertically, to easily get rid of any air bubbles. In one of the Perspex blocks a hole is drilled to allow for a syringe for drop injection. This hole is positioned in the midplane $(z=0)$ and points into one of the entrance channels, quite far from the centre of the device. A gear pump supplies a flow that is equally divided over the two opposed entrances. Using a frequency regulator and a computer the flow rate can be controlled; the maximum flow rate corresponds to a velocity gradient of $\mathrm{G} \approx 40 \mathrm{~s}^{-1}$. The exit flows are combined in the special control valve (discussed later) and lead into a tank from which the pump recirculates the fluid. About 1.5 liter of a model fluid is sufficient to operate the system. If the device is made suitable for molten polymers, it may be operated without a fluid tank (closed system) and with shorter and smaller tubes. The required volume of polymer melt may then be reduced to about 0.5 liter.

The centre of the cell is illuminated indirectly using a light source with a flexible optic fiber (Dolan-Jenner, Fiber Lite-3100) and a retroreflective film. The effect of the retroreflector is a more uniform distribution of the light beam, necessary to get a video image with minimal shading and optimal contrast; the contrast is only caused by the difference in refractive indices of the two liquid phases. A stereozoom microscope (Olympus SZ $4045 \mathrm{TR}$ ) is positioned perpendicularly to the front and back plates of the cell and magnifies the image in the range of 10 to $100 \times$. The microscope has a working distance of either 10 or $20 \mathrm{~cm}$. A colour camera (Panasonic WV CD 130/G) is mounted to the microscope that has a CCD-chip $(574(\mathrm{H}) \times 581(\mathrm{~V})$ elements; interlaced at $50 \mathrm{~Hz})$. The camera signal is split: one line is lead to a VHS videorecorder (Panasonic AG 6720 E) and the other one to an image processor (Philips SBIP; programmed for this application by Beltech, Eindhoven, The Netherlands), used for the position control of the drop (discussed later). The real-time image (original or processed) as well as an earlier recorded tape can be displayed on a colour monitor (Philips CM 8833).

\section{EXPERIMENTAL VERIFICATION OF THE FLOW FIELD}

\section{Laser Doppler Anemometry}

In the prototype cell for plane hyperbolic flow $(\mathrm{h}=2 \mathrm{~cm})$ the velocity field was examined using Laser Doppler Anemometry (LDA). Using a reference beam technique (Drain, 1981) with the laser beam directed parallelly to the $z$-axis, the velocity components $u$ and $v$ can be measured at any position within the flow field. Castor oil (Newtonian, with viscosity $0.7 \mathrm{Ns} / \mathrm{m}^{2}$ ) was used as a model liquid; the flow rate $Q$ was $5.88 \cdot 10^{-6} \mathrm{~m}^{3} / \mathrm{s}$.

In the midplane $(\mathrm{z}=0)$, at $25 \mathrm{y}$-positions the velocity profile $\mathrm{u}(\mathrm{x})$ was scanned and likewise at $25 \mathrm{x}$-positions the profile $\mathrm{v}(\mathrm{y})$. According to the flow model, all these curves should be linear. The bars in Fig. 4 indicate the length over which each of these curves is indeed linear. The total area where the flow field behaves linear (the drawn rhomb) is even larger than expected from the numerical simulations, viz. $3 \mathrm{~cm}$ along the axes of extension $(\mathrm{x})$ and compression $(\mathrm{y})$. Figure 5 shows the variation of the velocity component $v$ over the thickness $h$ between the flat front and back plates. The experimental data, at different positions $(x, y)$, coincide quite well with the parabolic fits (broken lines). Only further from the origin ( $C$ and $D)$ the measured profiles are a little flatter. As required, the extrema of $v(z)$ are linear with $y$ and independent of $x$. 


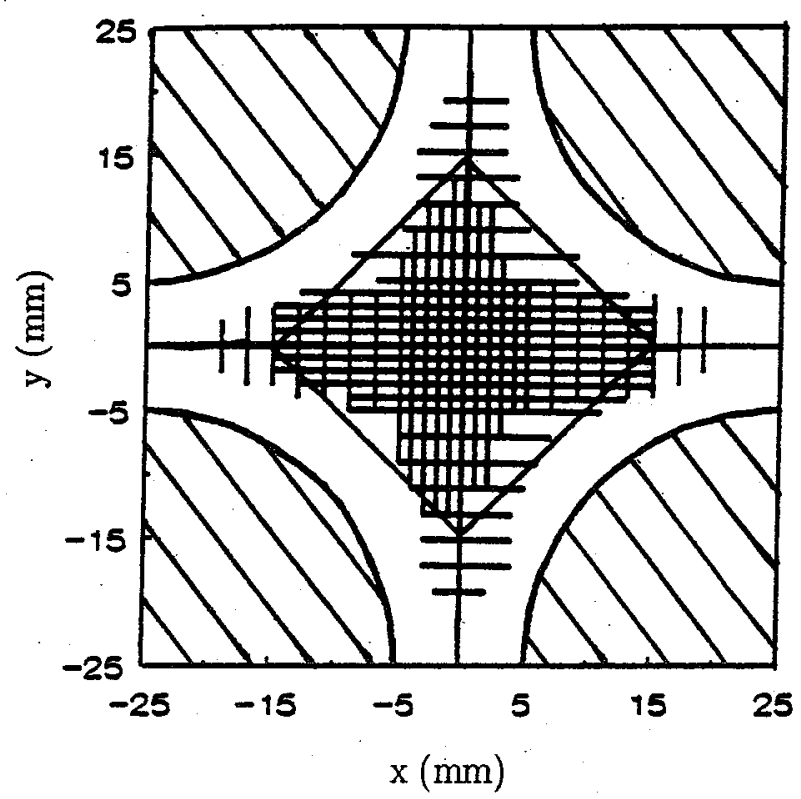

Figure 4. Region of constant velocity gradient determined from the length of the linear parts of the $\mathrm{u}(\mathrm{x})$ and $\mathrm{v}(\mathrm{y})$ profiles, measured using LDA.

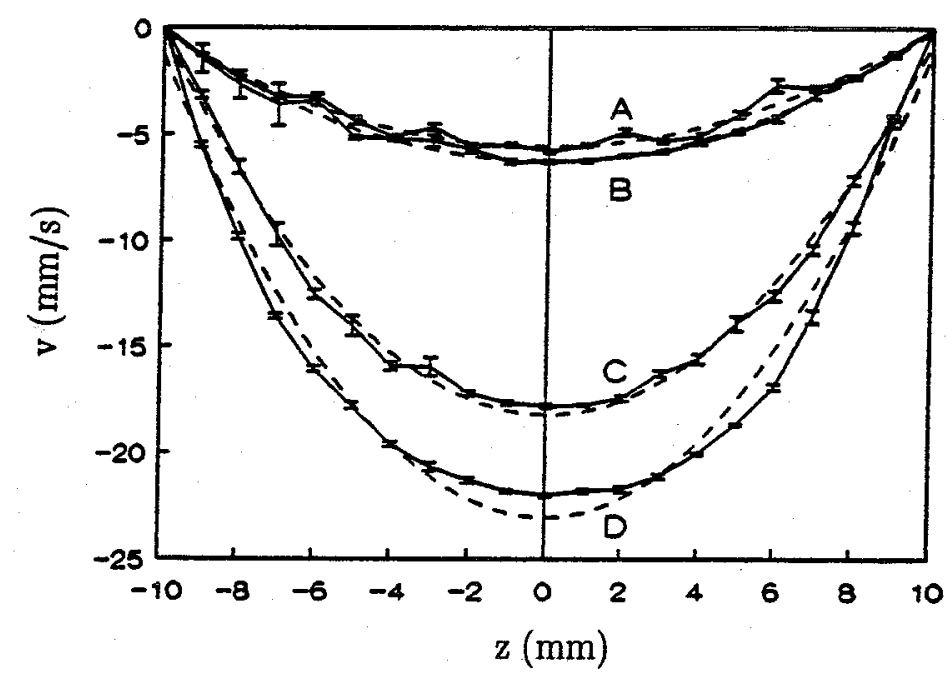

Figure 5. Velocity profiles $\mathrm{v}(\mathrm{z})$ at four positions $(\mathrm{x}, \mathrm{y}$ in $\mathrm{mm})$ : $\mathrm{A}(0,4), \mathrm{B}$ $(-5,5), \mathrm{C}(0,9), \mathrm{D}(0,15)$; the broken lines are second order polynomal fits.

\section{Calibration of the Velocity Gradient}

Knowing that the flow field fulfills the model, experiments were performed to calibrate the velocity gradient as a function of the flow rate supplied by the pump. The velocity component $\mathrm{u}$ linearly varies with the $\mathrm{x}$-coordinate $(\mathrm{u}=\mathrm{Gx})$. Upon integration it is clear that the $x$-coordinate of a fluid element or a passing drop increases exponentially with time $\left(x=x_{0} \cdot \exp (G t)\right)$. So, the velocity gradient $G$ in the midplane $(z=0)$ can be determined by plotting the $x$-coordinate of a small immiscible fluid drop, which passes through the central region, on a logarithmic scale versus the time. In the final design cell (thickness $\mathrm{h}=4 \mathrm{~cm}$ ) droplets were traced, using video recording, at different flow rates. Figure 6 shows the results, which are expressed by 


$$
\mathrm{G}\left(\mathrm{s}^{-1}\right)=0.135 \cdot 10^{6} \mathrm{Q}\left(\mathrm{m}^{3} / \mathrm{s}\right) \text {. }
$$

This is in reasonable agreement with the numerical prediction (broken line). For future drop deformation experiments, Eq. 9 seems the most reliable because the experimental method by which it was obtained is quite representative.

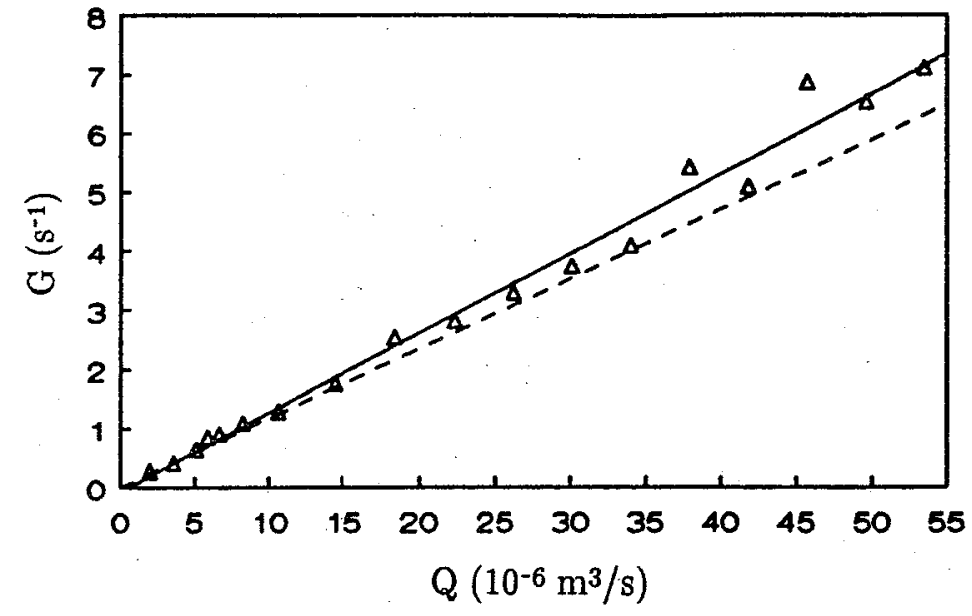

Figure 6. Velocity gradient determined by following the trajectory of a passing droplet as a function of the flow rate. The solid line is a linear fit through the experiments; the broken line gives the numerical prediction (Eq. 8).

\section{POSITION CONTROL OF THE DROP}

As mentioned before, the position of the drop at the stagnation point is unstable to disturbances; the drop tends to leave the device. For studying the deformation behavior of the drop, the flow has to be adjusted to keep the drop at the centre. The way to keep the drop close to the origin, is to frequently shift the stagnation point beyond the displaced drop, forcing it to return towards the origin. Originally, the four roll mill was used only for plane hyperbolic flow; the drops were positioned by varying the speeds of the left pair of rollers relative to those of the right pair, thus shifting the stagnation point along the $\mathrm{x}$-axis. This principle of position control can be applied to all strong linear 2-D flows.

In the opposed jets device a shift of the stagnation point is achieved by variation of the ratio of the exit flow rates. For plane hyperbolic flow this is illustrated in Fig. 7.a. The two entrance flows are kept equal to restrict the stagnation point to the $\mathrm{x}$-axis. Along the $x$-axis the stagnation point shifts to the exit with the smallest flow rate. The more the ratio of the exit flows differs from unity the further the stagnation point is shifted from the origin. By regularly adjusting the ratio of the exit flows and thus transferring the stagnation point beyond the centre of mass of the drop, the drop can be kept close to the centre of the device. In practice, the ratio of the exit flows is varied using a special valve (Fig. 7.b) in which both exits are combined to one flow. Rotating this valve increases one of the two flows and automatically decreases the other one. Thus, the rotation angle of the valve is the only variable for this $1-D$ control problem.

Many researchers (Taylor, 1934; Rumscheidt and Mason, 1962; Grace, 1971; van der Reijden-Stolk, 1989) report difficulties in keeping a drop at the centre of the four roll mill. Manual control only suffices for velocity gradients up to about $1 \mathrm{~s}^{-1}$; therefore, for the opposed jets device a computer-based control system was developed of which the sensor part is similar to that of Bentley 's (1985) control system for the four roll mill. The first step of the control cycle is the detection of the drop. An image processor grabs an image from the video camera and thresholds it, yielding a binary image representing a black drop on a white background. A contour operation is performed and the position of the drop centre is calculated as the mean of the positions of the contour pixels. Once the position of the drop is known, and thus the displacement from the centre of the device, a 
computer calculates the newly required position of the stagnation point and the corresponding angular position of the control valve. In the algorithm the time delay of the control cycle itself should be taken into account. Finally, a Maxon DC motor realizes the rotation of the control valve via a gear wheel reduction. A sample rate of about 25 control cycles per second results in a stable position of the deforming drop at the stagnation point; up to $\mathrm{G} \approx 5 \mathrm{~s}^{-1}$, the variation in the detected drop position is typically one pixel (the theoretical minimum), corresponding to, e.g., $0.03 \mathrm{~mm}$.

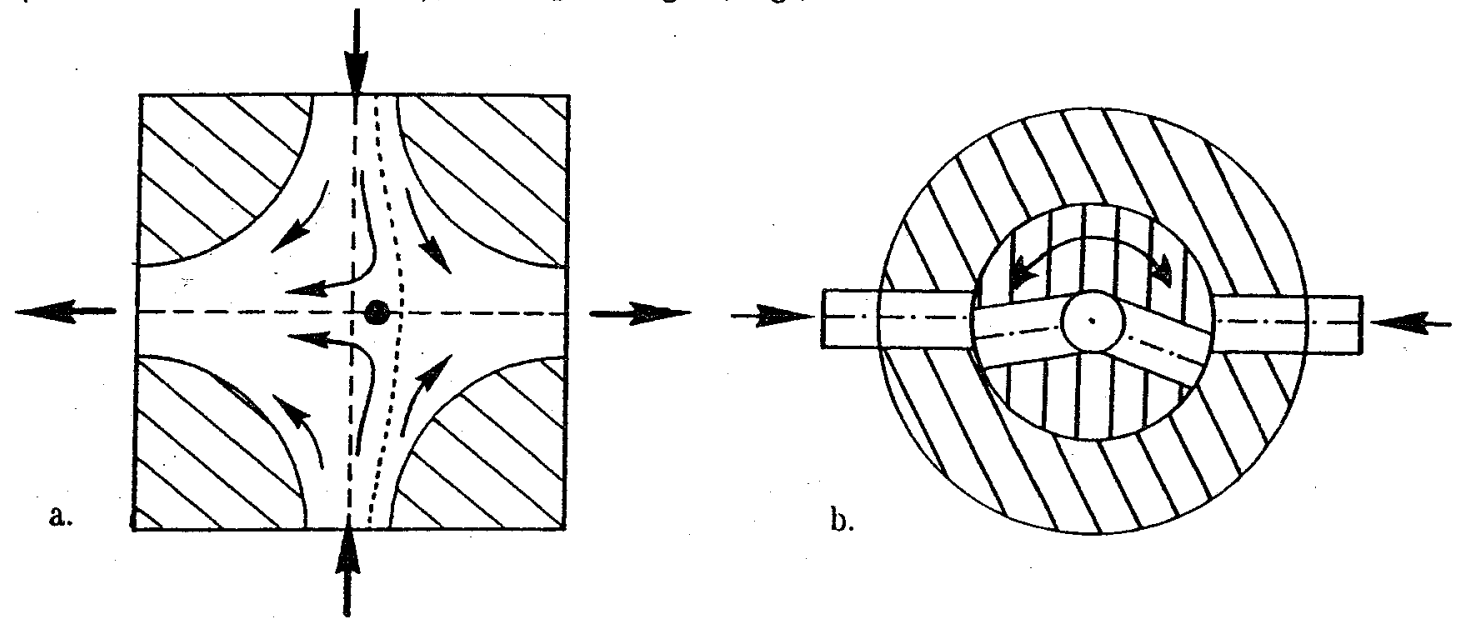

Figure 7. a. Principle of the control system for the drop position; the stagnation point is shifted due to variation of the ratio of exit flows. b. The control valve, combining the two exit flows to one that perpendicularly leaves at the centre.

\section{CONCLUSIONS}

Strong linear 2-D flows $(0<\alpha \leq 1)$ can be generated using the stagnation flow of two opposed jets. However, it is not possible to vary the type of flow continuously in one device because each flow type requires a different shaped cell. An opposed jets cell of only several centimeters $(r=2 \mathrm{~cm}$ and $b=1 \mathrm{~cm} ; \mathrm{Fig}$. 1) is suitable to study the deformation of a drop of the order of $1 \mathrm{~mm}$.

The flow pattern in a prototype cell for plane hyperbolic flow (with thickness $\mathrm{h}=2 \mathrm{~cm}$ ) was investigated using laser Doppler anemometry. In the midplane $(z=0)$ between front and back plates the flow is linear in a central region of at least $1 \mathrm{~cm}$ along the axes. Over the $z$-coordinate the velocities and the velocity gradient vary almost parabolically. Consequently, a thicker device is more favourable in view of deforming drops in a midplane of known velocity gradient; the final design cell was made $4 \mathrm{~cm}$ thick. Experimental calibration of the velocity gradient in this final cell agrees fairly well with the prediction from the $2-D$ simulations.

Using a special valve that combines the two exit flows in any desired ratio, the deforming drop can be kept near the stagnation point of the flow, which it tends to leave. At high values of the velocity gradient a computer controlled positioning system is indispensable. For this purpose an image processor is programmed for real-time $(25 \mathrm{~Hz})$ detection of the drop position. Optimal illumination is crucial to obtain sufficient contrast in the image. From the detected displacement of the drop, the required control action is calculated. Carrying it out, the drop is stabily positioned near the origin.

With respect to the four roll mill, conventionally used for experiments of drop deformation, the opposed jets device has a flow pattern that is in better accordance with the desired flow pattern (plane hyperbolic flow). Moreover, the opposed jets device is more suitable for studying polymer melts and viscoelastic test fluids. However, the four roll mill is more flexible concerning the generation of different types of flow, ranging from purely rotational $(\alpha=-1)$ to plane hyperbolic flow $(\alpha=1)$. 


\section{ACKNOWLEDGEMENT}

The authors want to thank DSM Research (Geleen, The Netherlands) who contributed to the costs of most of the equipment.

\section{REFERENCES}

Acrivos, A. (1983). The breakup of small drops and bubbles in shear flows. $4^{\text {th }}$ Int. Conf. on Physiochemical Hydrodynamics, Ann. N.Y. Acad. Sci., 404, 1-11.

Bentley, B.J. (1985). Drop deformation and burst in two-dimensional flows. Ph.D. thesis, California Institute of Technology, Pasadena, California.

Bentley, B.J. and L.G. Leal (1986). A computer-controlled four roll mill for investigations of particle and drop dynamics in two-dimensional linear shear flows. $J$. Fluid Mech., 167, 219-240.

Berker, R. (1963). Integration des equations du mouvement d'un fluide visqueux incompressible. In: Encyclopedia of physics (S. Flügge, ed.), Vol. VIII/2 Fluid dynamics, pp. 70. Springer Verlag, Berlin.

de Bruijn, R. (1989). Deformation and breakup of drops in simple shear flows. Ph.D. thesis, Eindhoven University of Technology, Eindhoven, The Netherlands.

Cuvelier, C., A. Segal and A.A. van Steenhoven (1986). Finite element methods and Navier-Stokes equations. Reidel Publishing comp., Dordrecht, Boston, Lancaster.

Drain, L.E. (1981). The laser Doppler technique. John Wiley \& Sons, New York.

Elemans, P.H.M. (1989). Modelling of the processing of incompatible polymer blends. Ph.D. thesis, Eindhoven University of Technology, Eindhoven, The Netherlands.

Fuller, G.G. and L.G. Leal (1981). Flow birefringence of concentrated polymer solutions in two-dimensional flows. J. Polym. Sci. Polym. Phys., 19 , 557-587.

Giesekus, H. (1962). Strömungen mit konstantem Geschwindigkeitsgradienten und die Bewegung von darin susp. Teilchen, Teil II: Ebene Strömungen und eine experim. Anordnung zu ihrer Realisierung. Rheologica Acta, Band 2, Heft 2, 112-122.

Grace, H.P. (1971). Dispersion phenomena in high viscosity immiscible fluid systems and application of static mixers as dispersion devices. Chem. Eng. Commun., 14, 225-277.

Janssen, J.M.H. (1991). Design and development of an opposed jets device. Internal report WFW-91.008, Eindhoven University of Technology, Dept. of Fundam. Mech.

Metzner, A.B. and A.P. Metzner (1970). Stress levels in rapid extensional flows of polymeric fluids. Rheologica Acta, Band 9, Heft 2, 174-181.

Meijer, H.E.H. and H.L. Bos (1989). Mischen und Kneten im Einschneckenextruder. Extruder im Extrusionsprozess, Tagung Bamberg, Mai 1989, VDI-Verlag, Düsseldorf.

Mikami, T., R.G. Cox and S.G. Mason (1975). Breakup of extending liquid threads. Int. J. Multiphase flow, 2, 113-138.

Müller, A.J., J.A. Odell and A. Keller (1988). Elongational flow and rheology of monodisperse polymers in solution. J. Non-Newtonian Fluid Mech., $\underline{30}$, 99-118.

Olbricht, W.L., J.M. Rallison and L.G. Leal (1982). Strong flow criteria based on microstructure deformation. J. Non-Newtonian Fluid Mech., 10, 291-318.

Ottino, J.M. (1989). The kinematics of mixing: stretching, chaos, and transport. Cambridge University Press, Cambridge.

Ottino, J.M. and R. Chella (1983). Laminar mixing of polymeric liquids; A brief review and recent theoretical developments. Polym. Eng. and Sci., 23-7, 357-379.

Rallison, J.M. (1984). The deformation of small viscous drops and bubbles in shear flows. Ann. Rev. Fluid Mech., $16,45-66$.

van der Reijden-Stolk, C. (1989). A study on deformation and breakup of dispersed particles in elong. flow. Ph.D. thesis, University of Technology Delft, The Netherlands.

Rumscheidt, F.D. and S.G. Mason (1962). Breakup of stationary liquid threads. J. Coll. Sci. $17,260-269$.

Segal, A. (1989). Sepran finite element package. Ingenieursburo Sepra, Leidschendam, The Netherlands.

Stone, H.A., B.J. Bentley and L.G. Leal (1986). An experimental study of transient effects in the breakup of viscous drops. J. Fluid Mech., $173,131-158$.

Taylor, G.I. (1934). The formation of emulsions in definable fields of flow. Proc. Roy. Soc., A 146, 501-523.

White, F.M. (1974). Viscous fluid flow. pp. 123, McGraw-Hill, New York. 